\title{
O LETRAMENTO LITERÁRIO E A ESCOLARIZAÇÃO DA LITERATURA INFANTOJUVENIL
}

Renan Marques Isse (UERJ)

Resumo: A literatura, se não apresentada aos alunos de forma adequada, pode perder a sua intenção enquanto disciplina escolar ao longo do convívio escolar do aluno. O presente artigo busca apresentar dois conceitos primordiais para que esse encontro do aluno-leitor com a literatura seja feito da forma mais adequada possível. Utilizaremos as noções de Letramento Literário e de Escolarização da Literatura, de Rildo Cosson e Angela Kleiman, respectivamente para guiar a problematização. Para tal, demonstrar-se-á a importância da articulação de diferentes níveis de conhecimento prévio como instrumento facilitador do processo de letramento.

Palavras-chave: Letramento Literário; Escolarização; Literatura; Leitor; Conhecimento prévio.

Abstract: Literature may lose its intention as scholar subject throughout school years, if not presented in an adequate way to the students. This paper intends to present two important topics so that this reunion between student-reader and literature may happen in the most ideal way possible. We will use Rildo Cosson's Literary Literacy and Angela Kleiman's Literature Schooling as topics in order to guide the discussion presented here. There will also be notes on how important it is to combine different levels of previous knowledge in order to make the literacy process easier.

Keywords: Literary Literacy; Literature Schooling; Literature; Reader; Previous knowledge.

\section{INTRODUÇÃO}

O processo de leitura de literatura Infantojuvenil é um caminho bifurcado e parcialmente contraditório. A visão desses tipos de livros voltados, sobretudo, para o público jovem e infantil possuem seus dogmas que resistem 
fortemente às perspectivas mais inovadoras de como explorar a obra literária, seja em sala de aula ou fora dela.

O comportamento mercadológico influencia bastante naquilo que é considerado literatura Infantojuvenil nos dias atuais. Marisa Lajolo (2000) diz que o aumento da escolarização da população criou a profissão do autor de livros infanto-juvenis. Além disso, contribuiu também para que seu trabalho fosse visto de forma tão autoral quanto o de escritor de clássicos ou best-sellers.

No entanto, esse percurso não pode ser analisado sem a presença do professor de literatura nas escolas. Veremos mais adiante que há uma perspectiva da escolarização literária em que o livro é fabricado para a escola, portanto, caberá ao professor a adesão ou não à obra literária.

O mercado literário passou a produzir também fichas de leitura guiadas, com sequências de atividades de leitura. Lajolo (2000) critica a postura de certos professores, pois há a pretensão de que alunos se tornem bons leitores com o auxílio dessas fichas. Ela defende que o professor é o facilitador da relação entre o aluno e a obra literária, portanto, ele deve ter um posicionamento ativo, e não terceirizar essa atividade para que autores e editores tomem seu papel em sala de aula. 
Essa prática é tendenciosa no ponto de vista de Lajolo (2000, p.73), pois

não só descompromete o estado das responsabilidades pela qualidade do ensino, como reforça o caráter reprodutor da escola, na medida em que tira da responsabilidade do professor, em diálogo com seus alunos e com suas leituras, o planejamento das atividades de leitura em que vai engajar-se com sua classe.

\section{O LETRAMENTO LITERÁRIO}

Conceito elementar para qualquer consideração sobre leitura literária e ensino é o que Rildo Cosson (2014) define como letramento literário. Para o autor, trata-se de um processo que supera a leitura simples, pois nesta o leitor apenas visualiza as palavras, decodifica-as, mas não é capaz de articulá-las em um todo significativo. O letramento literário, por outro lado, lida com todo tipo de conhecimento prévio que o aluno possui.

É, portanto, uma leitura engajada, que requer um posicionamento ativo do leitor, pois ele se apropria da obra, e, junto a ela, constrói significados próprios a partir daquilo que ele já sabe, suas leituras prévias e suas experiências pessoais.

Tal posicionamento do leitor, ao articular seus conhecimentos e, consequentemente, criar um panorama 
macro do texto lido, é o que, segundo Angela Kleiman (1989), pode-se dizer responsável pela retenção do que fora lido. $A$ partir de um experimento, a pesquisadora comprovou que a leitura simples - decorar um texto ou lê-lo de forma passiva - implica uma não compreensão do material.

Kleiman (1989) defende que a leitura não é um processo simplório, porque

[A] compreensão de um texto é um processo que se caracteriza pela utilização de conhecimento prévio: o leitor utiliza na leitura o que ele já sabe, o conhecimento adquirido ao longo da sua vida. É mediante a interação de diversos níveis de conhecimento, como o conhecimento lingüístico, o textual, o conhecimento de mundo, que o leitor consegue construir o sentido do texto. $E$ porque o leitor utiliza justamente diversos níveis de conhecimento que interagem entre si, a leitura é considerada um processo interativo. Pode-se dizer com segurança que sem o engajamento do conhecimento prévio do leitor não haverá compreensão.

(1989, p.13 - grifos da autora)

Marisa Lajolo concorda, e diz que

Ler um texto não é decifrar, como num jogo de adivinhações, o sentido de um texto. É, a partir do texto, ser capaz de atribuir-lhe significado, conseguir relacioná-lo a todos os outros textos significativos para cada um, reconhecer nele o tipo de leitura que seu autor pretendia e, dono da própria vontade, 
entregar-se a esta leitura, ou rebelar-se contra ela, propondo outra não prevista. (GERALDI, 2011, p.91 Apud LAJOLO, 1982, p.59)

A leitura é vista como um processo interativo, segundo as autoras, visto que há a combinação de diversos níveis de conhecimento. Aproximando a definição de Kleiman e a de Lajolo às ideias de Cosson, notam-se presentes os alicerces do letramento literário. Ressalte-se que o leitor deve usar os mesmos artifícios da compreensão de um texto não literário em uma obra literária, pois os mecanismos de inferência e de articulação de conhecimentos são os mesmos.

Cosson (2014) se opõe à ideia de que a escola use a leitura simples como atividade de leitura literária. No seu pensamento, "apenas ler é a face mais visível da resistência ao processo de letramento literário na escola" (COSSON, 2014, p.26). Notam-se dois fortes argumentos, portanto: a leitura simples e o letramento literário são processos antagônicos, e a escola deve privilegiar este em detrimento daquele.

O autor salienta que há uma preocupação, no entanto: a escola não deve limitar a leitura da obra por parte do aluno. Seu papel é o de facilitar a compreensão, usando de estratégias de incentivo à leitura. Ele considera a leitura como um ato solitário, mas ao mesmo tempo solidário. Quando 
alguém lê, geralmente o faz individualmente; a construção de sentidos, porém, trata-se de uma via de mão dupla:

Ler implica troca de sentidos não só entre o escritor e o leitor, mas também com a sociedade onde ambos estão localizados, pois os sentidos são resultado de compartilhamentos de visões do mundo entre os homens no tempo e no espaço. (COSSON, 2014, p.37)

Sem o engajamento e a articulação do conhecimento de mundo do leitor, sem que haja a troca de informações entre leitor e autor da obra, o sentido do texto não se faz completo. $\mathrm{O}$ gesto solidário que o autor usa para caracterizar a interpretação se faz verdadeiro, porque

Abrir-se ao outro para compreendê-lo, ainda que isso não implique aceitá-lo, é o gesto essencialmente solidário exigido pela leitura de qualquer texto. O bom leitor, portanto, é aquele que agencia com os textos os sentidos do mundo, compreendendo que a leitura é um concerto de muitas vozes e nunca um monólogo. (COSSON, 2014, p.37)

Kleiman concorda com essa posição. A autora diz que

[A] ativação do conhecimento prévio é, então, essencial à compreensão, pois é o conhecimento que o leitor tem sobre o assunto que lhe permite fazer as inferências necessárias para relacionar diferentes partes discretas do texto num todo coerente. Este tipo de inferência, que se dá como 
decorrência do conhecimento de mundo e que é motivado pelos itens lexicais no texto é um processo inconsciente do leitor proficiente. (1989, p.25 - grifos da autora)

\section{A SEQUÊNCIA BÁSICA}

Para que o processo de letramento literário obtenha êxito, é necessário que se siga uma sequência básica, que, segundo Cosson (2014), compõe-se de quatro estágios: motivação, introdução, leitura e interpretação.

A primeira etapa - a motivação - é uma maneira de se apresentar o texto aos alunos, preferencialmente de forma intersemiótica - uso de diferentes suportes - ou de forma intertextual, de modo a dialogar com os conhecimentos prévios dos estudantes. Cosson considera que o sucesso da abordagem literária depende de uma boa motivação. É válido ressaltar que as estratégias de motivação não devem ser apenas de ordem temática, apesar de ser a mais comum.

Enquanto apresentava a ideia de motivação, Cosson (2014) recebera críticas sobre um possível cerceamento da leitura dos alunos por parte do professor. De acordo com seus críticos, o processo tenderia a guiar a leitura do aluno para aquele aspecto que fora usado na motivação para despertar o seu interesse na obra. O autor, no entanto, diz que

a motivação prepara o leitor para receber o texto, mas não silencia nem o texto nem o 
leitor. [...] Naturalmente, a motivação exerce uma influência sobre as expectativas do leitor, mas não tem o poder de determinar sua leitura. (2014, p.56)

A introdução, etapa complementar, consiste em uma breve apresentação do autor, da obra literária, do contexto literário e de quaisquer outras informações que o professor julgue fortemente pertinente. Seu objetivo é de promover o interesse pela leitura, portanto, a introdução deve ser algo sucinto, sem que haja excesso de informações de que o aluno não precise saber. Deve haver uma seleção criteriosa de elementos, de modo a não tornar a aula enfadonha nem criar mais barreiras para o contato do aluno com a literatura na escola.

Já na leitura, os alunos devem ler a obra, individual ou coletivamente. Independente de como essa leitura se dará, o professor tem papel primordial: ele é o regente desse concerto; precisa, portanto, acompanhar a leitura dos alunos, uma vez que esse trabalho de leitura em sala de aula tem um propósito que não deve ser perdido de vista.

Não cabe ao professor apenas tomar conta; ele deve estar pronto para ajudar o aluno em eventuais dificuldades e elaborar estratégias para facilitar o contato do leitor com a obra. Cosson (2014) considera a leitura como a etapa 
diagnóstica, ou seja, o momento em que o professor pode avaliar de perto o se há ou não dificuldades e obstáculos na apropriação desse texto.

A interpretação, o último estágio da sequência básica de Cosson, é a ponte entre o texto e os já mencionados conhecimentos prévios do aluno. É nessa etapa em que o professor pode trabalhar questões relacionadas à compreensão de texto de modo geral. Ao articular toda a sua bagagem cultural formal e informal, o leitor é capaz de criar significados para o texto lido, o que comprova que de fato a obra literária foi entendida.

\section{A LEITURA LITERÁRIA NA ESCOLA}

Magda Soares (2006) define dois modos que a escola usa para trabalhar a literatura em sala de aula. Uma dessas possibilidades é quando a escola incorpora a literatura infantil e a transforma em um objeto escolarizado, isto é, que precisa ser transformado de modo a atingir um objetivo próprio. A outra possibilidade trabalha com obras infantojuvenis sendo produzidas para a escola, ou seja, o texto já vem moldado e direcionado para as pretensões pedagógicas da escola.

A literatura escolarizada possui um posicionamento ativo da escola para que esta adapte aquela de acordo com seus objetivos, ao passo que produção literária voltada para a 
escola não requer que a escola e o corpo docente preparem o texto para os alunos - ele já vem feito sob medida para os objetivos escolares.

Lajolo (2000) diz que um dos papeis da literatura Infantil na escola é expandir conhecimentos, atitudes, valores, sentimentos e comportamentos, de modo a participar da formação dos estudantes - um viés pedagógico da literatura. Coelho (2000) concorda com esse posicionamento, e defende que há dois caminhos a se seguir com o ensino literário na escola. Enquanto um é aquele definido por Lajolo, que tem como norte a transmissão de valores já consolidados pela sociedade ao longo dos anos, a proposta atual de Coelho visa problematizar aquilo que está sendo lido.

Coelho defende o papel de agente de formação que a literatura, especialmente a infantil, tem na sociedade atual, quando defende que o papel essencial da literatura - infantil ou não - é o de atuar sobre as mentes e os espíritos, ou seja, "alertar ou transformar a consciência crítica de seu leitor/ receptor" (COELHO, 2000, p.29 - grifos da autora).

É imprescindível associar essas visões de literatura infantil à articulação de conhecimentos necessária para que a problematização seja efetiva. Segundo Rildo Cosson,

[O]s livros, como os fatos, jamais falam por si mesmos. O que os fazem falar são os 
mecanismos de interpretação que usamos, e grande parte deles são aprendidos na escola. [...] No ambiente escolar, a literatura é um lócus de conhecimento e, para que funcione como tal, convém ser explorada de maneira adequada. A escola precisa ensinar o aluno a fazer essa exploração. (2014, p.26)

Para que o leitor possa mergulhar confortavelmente no texto a ser lido, ele precisa engajar seus conhecimentos prévios, para, junto ao texto, construir seu significado.

Eis a função da escola e do professor: eles são os principais agentes no processo de facilitação do contato do aluno com o texto literário. Portanto, um dos posicionamentos mais elementares é o de retirar a literatura do seu posto sagrado, inalcançável, que mais lhe causa problemas do que soluções. Para atingir esse objetivo, fez-se necessária a escolarização do texto literário.

A literatura era costumeiramente abordada em sala de aula como pretexto para atividades de cunho gramatical. Geraldi (2011) não condena o uso do texto literário como ponto de partida para outras atividades em sala de aula, mas nota-se que a literatura é vista de forma instrumental, de modo que ela é usada para atingir um objetivo que não lhe pertence.

Para Lajolo, 
[O] primeiro momento de liberação do texto literário da gramatiquice aguda coincidiu com a adesão a uma espécie de modelo simplificado de análise literária: questionários a propósito de personagens principais e secundários, identificação de tempo e espaço da narrativa, escrutínio estrutural do texto. (2000, p.70)

Lajolo explica que a literatura, nesse momento, começou a ser vista não como um suporte textual clássico que permita demonstrar certas normas gramaticais de acordo com a escrita de autores literários, e sim como uma disciplina ensimesmada, isto é, um campo do saber que tem propósito e objetivos próprios.

Apesar de se tratar de uma forma técnica de leitura, esse é um marco a ser celebrado. Em A escolarização da literatura infantil e juvenil, Magda Soares critica fortemente o modelo em que a literatura é apresentada aos alunos em sala de aula. Sua análise recai nas séries iniciais do Ensino Fundamental primeiro ao quarto ano.

Soares (2006) define a escolarização da literatura como um processo inevitável, porque ele é a essência da escola. Segundo a autora, trata-se da

ordenação de tarefas e ações, procedimentos formalizados de ensino, tratamento peculiar dos saberes pela seleção, e conseqüente exclusão, de conteúdos, pela ordenação 
e seqüenciação desses conteúdos, pelo modo de ensinar e de fazer aprender esses conteúdos. (2006, p.21)

Fenômeno, portanto, natural, a escolarização da literatura enquanto processo não deve ser criticado ou negado. 0 que, no entanto, tem todo o direito de receber críticas fortes é o processo errôneo e inadequado da escolarização literária. Soares (2006) aponta três instâncias principais de inadequação do processo: a biblioteca, a leitura de literatura e a leitura de textos.

A biblioteca escolar é um local que armazena e permite o contato com a literatura fora da sala de aula. Deve-se levar em consideração aspectos organizacionais do contato com a leitura, que se tornam manifestações políticas. A seleção e a disposição de livros ao longo das prateleiras é uma característica essencialmente política, pois trata de algumas obras que estão de fácil acesso, enquanto outras se escondem nas prateleiras mais altas ou mais distantes. Todas as perguntas que envolvem a leitura - como ler, onde ler, quanto tempo se pode ler, quem indica o livro, quais critérios envolvem essa indicação de leitura, quais autores, gêneros, obras, séries, alunos - tudo isso é um comportamento político.

A leitura de literatura na escola, segundo Soares (2006), nunca será a leitura simples ou a leitura enquanto fruição 
do texto, que geralmente os alunos fazem em casa. Predominantemente há sempre a necessidade de comprovar a leitura por meio de atividades e avaliações dos mais variados tipos. Justifica-se, portanto, que o processo de escolarização da literatura é algo inevitável, mas o objetivo em sala de aula é que ela aconteça de modo adequado e pertinente.

Aleitura de textos é a terceira instância, e a mais privilegiada por Soares. Ao longo dessa sessão, ela aborda quatro formas grosseiras de se inserir o texto literário. Em comum, nota-se que a literatura é sempre usada como pretexto para algo, geralmente o ensino de normas gramaticais, componentes lexicais, ortográficos, em suma, raríssimas são as vezes em que se usa o texto para ensinar a literatura. Percebese também que a literatura é instrumentalizada: ela vira o suporte privilegiado para ensinar gramática.

Gêneros essencialmente vinculados à realidade do aluno de primeiro a quarto ano do Ensino Fundamental, a biografia, o diário, as memórias são preteridos para que predominem textos narrativos e poemas. A abordagem desse último gênero, no entanto, é totalmente técnica: muito se fala dos aspectos estruturais - rimas, versos, estrofes - e se ignora a interação que uma boa atividade de leitura merece. Soares ressalta que essa não-interação pode levar o afastamento das crianças às poesias. 
A seleção constante dos mesmos autores e obras é um desserviço à escolarização adequada da literatura. Soares (2006) justifica que dessa forma a escola cria e reforça conceitos excludentes de que apenas determinados autores e textos - geralmente os que são trabalhados na escola apenas - são constituintes da literatura, ou seja, apenas o cânone é válido e autores não canonizados são marginalizados pela escolarização da literatura. A autora defende que faltam critérios justos para a seleção do corpus a ser estudado em sala de aula.

Outra forma de escolarizar erroneamente a literatura se dá com a incorporação do que Soares (2006) chama de pseudotexto, mais uma vez usando a literatura como instrumento para o ensino de gramática. Para que algo tenha o status de texto, é necessário que apresente unidade semântica (coerente) e formal (coesa). Não é o caso dos pseudotextos, que, segundo Soares (2006), é produzido pelo próprio autor do livro didático. Esse tipo de texto demonstra um caráter a-textual, uma vez que não apresenta coerência nem coesão.

A crítica da autora recai sobre o uso desse "ajuntamento" de palavras pois "muito freqüentemente não se cuida de que o fragmento apresente, também ele, textualidade, isto 
é, que apresente as características que fazem com que uma seqüência de frases constitua, realmente um texto" (SOARES, 2006, p.31 - grifos da autora).

Os fragmentos apresentam geralmente o ciclo inicial da narrativa e omitem o que acontece em seguida. O leitor fica na expectativa de saber o que acontece ao longo da história. Como não recebe as informações de que sente falta, desenvolverá uma ideia inadequada de literatura. Além disso, perde-se o sentido global da obra: a exposição de apenas uma sequência descontextualiza-a e pode guiar a interpretações e inferências erradas acerca dessa obra.

A última forma de inadequação na escolarização da literatura apontada por Soares é quando se retira o texto de seu suporte original (a obra literária) e ele é realocado no livro didático. Sabe-se que o livro de literatura infantil é composto de diversos elementos extratextuais, a citar as diversas ilustrações que dialogam com o texto, a diagramação específica do gênero, protocolos de leitura individuais, entre outros. Tais elementos não são respeitados na transposição de um suporte para o outro.

Ressalte-se que, em se tratando de suportes e gêneros diferentes, naturalmente se fazem necessárias algumas adaptações. Soares (2006) diz que se deve manter a sua essência. Em outras palavras, "se é inevitável escolarizar a 
literatura infantil, que essa escolarização obedeça a critérios que preservem o literário, que propiciem à criança a vivência do literário, e não de uma distorção ou caricatura dele" (2006, p.42).

Ela considera a simplificação excessiva e desnecessária de vocabulário, a descontextualização do texto e da imagem e a variação de gêneros textuais como erros crassos do processo de escolarização da literatura.

\section{CONSIDERAÇÕES FINAIS}

De acordo com Kleiman (1989), apenas o engajamento dos conhecimentos prévios e inferências - isto é, uma postura ativa enquanto leitor - é capaz de demonstrar que de fato há entendimento daquilo que fora lido. Essa postura ativa corrobora as palavras de Cosson, ao demonstrar que o letramento literário é vital para a postura de um leitor crítico, capaz de entender todas as nuanças apresentadas ao longo do texto.

Quando o leitor é capaz de buscar em seu conhecimento de mundo estratégias que facilitem a compreensão do texto, a proficiência leitora foi atingida. No entanto, esse processo, que caminha lado a lado com a escolarização do texto literário, encontra alguns obstáculos apresentados e duramente criticados por Soares (2006). A autora indica 
que quando esse processo é mal realizado, ele pode deixar marcas profundas na relação do aluno com a literatura.

\section{REFERÊNCIAS}

COELHO, Nelly Novaes (2000). "A literatura infantil: abertura para a formação de uma nova mentalidade". In: Literatura infantil: teoria, análise e didática. São Paulo: Moderna, p.14-45.

COSSON, Rildo (2014). "Aula de literatura: o prazer sob controle?" In: . Letramento Literário: teoria e prática. 2.ed. São Paulo: Contexto, p.24-30.

COSSON, Rildo (2014). "A sequência básica". In: . Letramento Literário: teoria e prática. 2.ed. São Paulo: Contexto, p.51-73.

GERALDI, João Wanderley (2011). Prática da leitura na escola. São Paulo: Ática.

KLEIMAN, Angela (1989). "O conhecimento prévio na leitura". In: KLEIMAN, Angela. Texto e leitor: aspectos cognitivos da leitura. Campinas: Pontes, p.13-27.

LAJOLO, Marisa (2000). "Literatura infantil e escola: a escolarização do texto". In: . Do mundo da leitura para a leitura do mundo. 6.ed. São Paulo: Ática, p.66-74.

SOARES, Magda (2006). "A escolarização da literatura infantil e juvenil". In: EVANGELISTA, Aracy Alves Martins; BRANDÃO, Heliana Maria Brina; MACHADO, Maria Zélia Versiani. (Orgs). A escolarização da leitura literária: o jogo do livro infantil e juvenil. 2.ed. Belo Horizonte: Autêntica, p.17-48.

Renan Marques Isse é Doutorando em Literatura Comparada e Teoria da Literatura e Licenciando em Letras: Português/Italiano pela Universidade do Rio de Janeiro (UERJ).

ORCID iD: https://orcid.org/0000-0002-5707-7493 